Motrivivência Ano XXV, No 41, P. 206-222 Dez./2013

http://dx.doi.org/10.5007/2175-8042.2013v25n41p206

\title{
CORPO COMUNICATIVO: analisando a comunicação corporal por meio da exploração espacial do educador
}

\author{
Djavan Antério ${ }^{1}$ \\ Pierre Gomes-da-Silva²
}

\section{RESUMO}

A partir da perspectiva do corpo como percepção e expressão do sujeito no mundo, o presente artigo analisa a comunicação corporal do educador como fonte primária e constante de informação. Trata-se de uma pesquisa descritiva, de abordagem qualitativa, do tipo participante, com 28 professores de educação física. Os resultados evidenciaram a concretude de uma ação corporal possível de ser provocada e alterada, vislumbrando o potencial pedagógico no que se refere à devida e consciente exploração do espaço pelos sujeitos pesquisados. Concluiu-se ainda que o entorno espacial caracteriza-se como cenário pedagógico àquele que se propõe a ensinar.

Palavras-chave: Educação; Educação Física; Comunicação corporal.

1 Mestre em Educação. GEPEC/UFPB. João Pessoa/Paraíba, Brasil. E-mail: djavananterio@gmail.com.

2 Doutor em Educação. GEPEC/UFPB. João Pessoa/Paraíba, Brasil.

E-mail: pierrenormandogomesdasilva@gmail.com. 


\section{INTRODUÇÃO}

O artigo apresentado corresponde ao resultado de dois anos de pesquisa em nível de mestrado (stricto sensu). Em linhas gerais, investigou-se as repercussões pedagógicas advindas da intervenção na Comunicação Corporal do educador físico atuante no âmbito escolar. Valendo-se da perspectiva do corpo como percepção e expressão fundamental para a inter-relação do sujeito consigo e com os outros, identificamos alguns problemas relacionados à comunicação enfrentados por professores de Educação Física no que concerne à sua prática docente. Formulamos então uma compreensão acerca da Comunicação Corporal, a qual serviu como base para todo o estudo. Num esforço de síntese, trata-se da capacidade de o sujeito comunicar-se corporalmente, recorrendo de forma consciente e estratégica à linguagem não-verbal (ANTÉRIO, 2011).

Além da defesa da dissertação, para a apresentação dos achados, resolvemos fragmentar os resultados e apresentá-los em formato de artigos. Isso por compartiIharmos do pensamento de que a difusão do conhecimento deve ser a mais ampla e de fácil acesso possível. Mais que isso, sem custos financeiros para aquele que busca aprender. Ademais, partimos do pressuposto que adotando tal procedimento, evitaríamos condensar tudo o que fora produzido, certamente comprometendo detalhamentos fundamentais para a compreensão da pesquisa realizada.

Dessa forma, levando em consideração as limitações que há nas normas dos periódicos (número de páginas, caracteres, etc) e a possibilidade de aprofundarmos mais as análises e discussões, produzimos uma espécie de "trilogia", apresentando os resultados do estudo por meio dos três indicadores de comunicação corporal: Gestual, referindo-se a gestualidade do educador; postural, correspondendo a postura do educador; e espacial, dizendo respeito à ocupação/exploração do espaço pedagógico no qual o educador atua. Estruturamos, portanto, três artigos específicos: (1) "Corpo comunicativo: analisando a comunicação corporal por meio da gestualidade do educador", já publicado e disponível nas referências; (2) "Corpo comunicativo: analisando a comunicação corporal por meio da postura do educador", o qual se encontra em fase de avaliação; e (3) "Corpo comunicativo: analisando a comunicação corporal por meio da exploração espacial do educador", correspondendo a este manuscrito.

Uma vez sendo tais artigos oriundos de uma mesma intervenção científica, é importante frisar algumas semelhanças entre eles. Contudo, cada qual de sua maneira, apresenta aspectos e perspectivas que subsidiam a leitura da Comunicação Corporal através de uma ótica específica. Isso pelo fato de lidarmos com canais de comunicação distintos. O intuito em adotarmos tal procedimento se reforça no maior aprofundamento analítico pós-campo e a possibilidade de ampliarmos o processo crítico-reflexivo sobre a temática.

No que se refere o tema central do estudo, apresentamos uma leitura do movimentar-se sustentada em princípios amplamente defendidos por autores que veem além da ação motora. No campo da Educação Física, podemos citar Freire (2009); Kunz (2004); e Medina (2001). Já na filosofia, temos Foucault (1987), defendendo o corpo como fonte de prazer; e Merleau-Ponty (1999), considerando-o 
como um "ponto de vista sobre o mundo", sendo ele fonte sensitiva do que acontece no mesmo. Conectamo-nos ainda ao campo das artes, com, por exemplo, Bertherat (2008) e a consciência de si; bem como Laban (1978) e seu já consolidado método de análise de movimento.

De forma a manter um afinamento com o que defendemos, analisamos a comunicação corporal do educador de maneira extensiva, isto é, considerando aquela que se dá consigo mesmo, com os alunos e com o entorno educativo no qual se insere (objetos, espaço, tempo). Na literatura, encontramos poucos estudos com uma abordagem similar. Na realidade, a temática da Comunicação Corporal é trabalhada de forma diluída, apoiada em diferentes conceitos, ligada a terminologias específicas e diversificadas. Autores como Corraze (1982), Rector e Trinta (1985), Knapp e Hall (1999) e Glusberg (2003) trazem aspectos que podem, respeitando as proporções, se entrelaçarem. Acreditamos que é exatamente nisso que nos ancoramos, a possibilidade de construir, coletivo e colaborativamente, uma teoria mais consolidada.

Neste contexto de plurais concepções, em que pensamentos dialogam e se auxiliam, objetivamos identificar as efetivas repercussões pedagógicas obtidas pela aplicabilidade de um Programa de Técnicas Corporais na capacidade comunicativa corporal do educador. Analisando a ocupação espacial dos professores ao se comunicarem corporalmente e estruturando junto a eles uma atitude corporal mais sólida e ativa no processo socioeducativo, focamos, neste artigo, a análise na capacidade de o sujeito explorar o espaço em que se insere. Para isso, adotamos a perspectiva trazida por Glusberg (2003), em que o corpo passa pela prática de se comunicar através de suas "inervações", isto é, o corpo provocado e explorado em sua máxima potencialidade. Seguindo o que nos apresenta Pease e Pease (2005), consideramos a linguagem corporal um importante elemento no processo comunicativo entre seres sociais. Logo, entendendo o que o corpo diz, entendemos melhor o que os outros nos têm a dizer.

\section{CONTEXTUALIZAÇÃO METODOLÓGICA}

Recorrendo a exploração espacial enquanto um canal de comunicação, investigamos as repercussões pedagógicas da capacidade comunicativa corporal do educador físico. A pesquisa, por sua vez, configura-se como descritiva, de abordagem qualitativa, do tipo participante, cuja técnica de coleta se deu por meio de seminários, oficinas corporais, observação e diário de campo, com professores de educação física da rede municipal de Cabedelo, no estado da Paraíba/Brasil.

Como citamos na parte introdutória, valendo-nos da perspectiva do corpo como percepção e expressão fundamental para a inter-relação do sujeito, de forma empírica, identificamos alguns problemas relacionados à comunicação enfrentados por professores de Educação Física no que concerne à sua prática docente. São eles: (a) pouca atitude corporal ao comunicar-se; (b) adaptação ao meio em que está inserido; e (c) timidez ao expressar-se. A partir daí, organizando e sistematizando a ações de intervenção que viria a posteriori,eis que se caracterizou nossa questão-problema: Em que medida a comunicação corporal pode repercutir pedagogicamente na capacidade interventiva do educador? 
Dando continuidade ao processo, realizamos um levantamento bibliográfico de estudos referentes à temática em questão, seguindo de uma investigação qualitativa descritiva de campo por meio de questionários ${ }^{3}$ temáticos aplicados aos sujeitos da pesquisa. Na sequência, realizamos o seminário vivencial, o qual serviu como experimento para a coleta dos dados.

O campo de intervenção da pesquisa foi constituído por professores de educação física da rede pública de ensino e, como critério de inclusão, consideraram-se todos os professores efetivos, ativos no período do seminário (fase de coleta de dados) e que estavam trabalhando diretamente com os alunos. Foram desconsiderados os professores em algum tipo de afastamento ou licença no período da coleta dos dados, que realizavam atividades administrativas e aqueles que não concordaram em participar do estudo. Por fim, participaram
28 professores no total, sendo 15 do sexo feminino e 13 do sexo masculino.

O processo interventivo se deu por meio do Seminário de Vivências Corporais, o qual foi estruturado levando em consideração o período de que estaríamos juntos aos professores. Diante do que já tínhamos até o dado momento, elaboramos um planejamento que subsidiasse o cronograma estruturado e separamos os conteúdos que iríamos trabalhar em quatro oficinas distintas: Oficina I, Corpo em Ação; Oficina II, Corpo Gestual; Oficina III, Corpo Postural; Oficina IV, Corpo Espacial. Todas elas, com exceção da primeira, atendiam à especificidade de cada categoria avaliativa assim como se aplicavam por meio dos canais de comunicação preestabelecidos. Vale frisar que cada categoria se contextualizada por uma respectiva circunstância pedagógica, tal como aponta o quadro a seguir.

Quadro 1: Estrutura pedagógica adotada

\begin{tabular}{|c|c|c|c|}
\hline OFICINA & $\begin{array}{c}\text { CATEGORIA } \\
\text { AVALIATIVA }\end{array}$ & $\begin{array}{c}\text { CIRCUNSTÂNCIA } \\
\text { PEDAGÓGICA }\end{array}$ & $\begin{array}{c}\text { CANAL DE } \\
\text { COMUNICAÇÃO }\end{array}$ \\
\hline$I^{*}$ & --- & -- \\
\hline II & Corpo Gestual & Explicação no início da aula & Gestos \\
\hline III & Corpo Postural & Procedimento durante a aula & Postura \\
\hline IV & Corpo Espacial & Deslocamento durante a aula & Espacial \\
\hline \multicolumn{2}{|c|}{$*$ A Oficina I correspondeu ao processo de intervenção introdutória da proposta. } \\
\hline
\end{tabular}

O quadro acima representa a correlação que fizemos para estruturarmos as oficinais a serem trabalhadas. Para a circunstância pedagógica Explicação no Início da Aula, adotamos o canal de comunicação dos Gestos, que envolve a

3 Ver apêndices A e B. 
linguagem e a expressividade corporal entre pessoas ou com objetos. Em se tratando da circunstância Procedimento Durante a Aula, valemo-nos do canal de comunicação da Postura, que envolve os movimentos corporais que podem fornecer pistas seguras acerca da intencionalidade ou até mesmo do estado emocional do emissor. Por fim, para a circunstância Deslocamento Durante a Aula, valemo-nos do canal de comunicação Exploração do Espaço, que envolve a capacidade de o sujeito explorar de forma mais eficaz o espaço no qual está inserido (ARGYLE, 1988; CORRAZE, 1982). Ratificamos que as oficinas do seminário eram compostas tanto pela parte teórica (textos, artigos científicos, ilustrações) como pela parte prática (atividades, dinâmicas, jogos), buscando instigar e fomentar a utilização da comunicação corporal em todo o processo comunicativo. Cada oficina foi aplicada durante o período de um mês, sendo dividida em quatro momentos.

$\mathrm{Na}$ Oficina IV, foco deste artigo, trabalhamos sob a categoria avaliativa Corpo Espacial, contando com o auxílio do professor Elias Lopes ${ }^{4}$. Contextualizados pela circunstância pedagógica Deslocamento Durante a Aula, partimos da perspectiva do corpo como ferramenta interativa, que age e interage com o meio no qual está inserido (outras pessoas, objetos, ambientes).

Especificamente para nosso estudo, denominamos de Espaço Pedagógico o espaço que compreende aquele que ensina e aquele que aprende, definindo certa relação entre eles (FRERE, 1999). Baseando-nos em estudos referentes à performance cênica do ator, vinculamos a técnica de explorar o palco ao procedimento didático na sala de aula. Adotamos conceitos e pensamentos oriundos de Argyle (1988), Koudela (1992), Novelly (1994) e Katz e Greiner (2004). Nossa intervenção contemplou uma expansão do corpo no espaço, demonstrando e praticando o corpo presente como corpo que se faz presente.

Em relação à categoria avaliativa, verificamos a capacidade de o sujeito explorar o espaço em que está inserido priorizando a dimensão espacial horizontal (perto e longe). Partimos da perspectiva trazida por Novelly (1994), na qual o professor é o elemento fundamental no espaço pedagógico, não podendo ele existir sem um espaço onde se desenvolva. Segundo a autora, o espaço pedagógico não deixa de ser um espaço de jogo, definido por uma prática psíquica e física. Ele é o lugar dos corpos dos atores, é a imitação de um lugar do mundo, jogando com a presença de objetos e de pessoas reais.

A avaliação procedeu-se a partir de movimentações performáticas (mímicas) contextualizadas por uma frase temática em um período de 5 minutos. A frase era apenas o ponto de partida para a performance, não havendo a necessidade de estar vinculada por completo ao tema oferecido. Nessa prática corporal padrão, diferentemente da prática similar, não houve a interação direta com os observadores. A intenção foi avaliar a noção de espaço tida pelo professor e se este, conscientemente ou não, ocupava o máximo de espaço possível durante a movimentação.

4 Mestre em Artes Cênicas e Professor do Departamento de Artes Cênicas da Universidade Federal da Paraíba. 


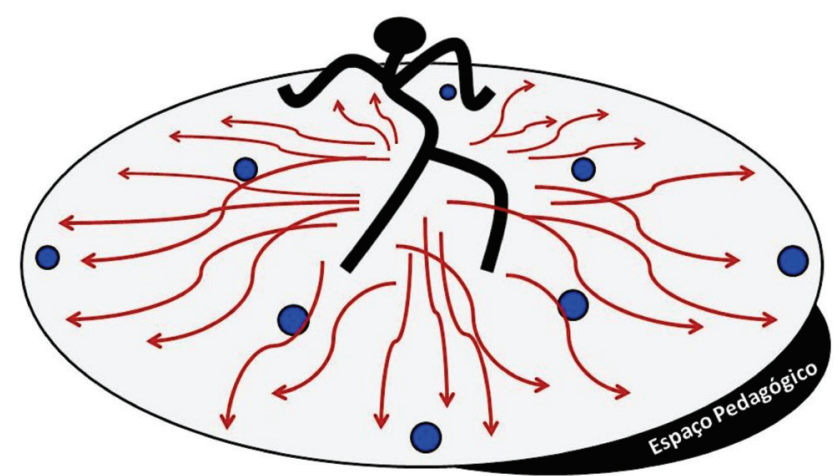

Figura 1: Espaço Pedagógico

Para a menção, quanto mais pontos demarcados fossem atingidos durante a movimentação, maior seria a eficácia da atuação do professor: (a) 0 a 3 pontos - Pouco espaço explorado; (b) 4 a 6 pontos - Razoável espaço explorado; (c) 7 a 8 pontos - Considerável espaço explorado. Como estratégia didática, fomentamos uma discussão acerca da performance realizada. Ao realizador, indagávamos sobre suas sensações ao realizar uma movimentação aleatória, intuitiva, o que ou em que pensava no dado momento. Ao grupo observador, colhíamos opiniões, sugestões, sensações sentidas ao observar a performance do colega. A intenção foi provocar um debate sobre o canal de comunicação em questão (exploração do espaço) e sua ligação com a Comunicação Corporal.

Para a coleta dos dados, contamos com o auxílio de um protocolo desenvolvido especificamente para a pesquisa. Diz respeito a uma ferramenta de observação que satisfez nossa pretensão em verificar o nível de comunicação corporal de nossos atores por meio dos canais de comunicação (gestual, postural e espacial), avaliando as repercussões obtidas após a participação no seminário. Intitulamos tal ferramenta de Protocolo de Observação do Corpo Comunicativo (POCC ${ }^{5}$ ). Caracterizamos diferentes tipos de categorias avaliativas, desenvolvidas com base no arcabouço teórico apresentado, sendo cada uma delas adequada às intencionalidades pré-estabelecidas, sendo ainda contextualizada por determinado canal de comunicação. No total, tivemos três categorias: Corpo Gestual, desenvolvida à luz dos estudos de Corraze (1982), Knapp e Hall (1999), Glusberg (2003); Corpo Postural, subsidiada por estudos de Bertherat (2008) e Laban (1978); e Corpo Espacial, ancorando-se em Argyle (1988) e Katz e Greiner (2004).

No tocante a análise dos dados, procedemos junto ao sujeito pesquisado por meio de sua conjuntura corporal, ou seja, reconhecendo-o através de seu construto 
performático e sua linguagem não-verbal. A partir do Indicador de Comunicação (IC) recorrido na pesquisa Exploração Espacial, definimos fatores considerados por nós inerentes ao ato de movimentar-se, bem como a processo de ocupação do espaço no qual o sujeito está inserido. Para a sistematização da análise, baseamo-nos em estudos de Argyle (1988); e Katz e Greiner (2004), os quais serviram de suporte teórico para o construto interventivo da pesquisa.

Coletadas as informações perpassadas pela ocupação espacial do "corpo-sujeito", a análise prosseguiu por procedimentos sistemáticos e objetivos para assim obtermos indicadores (qualitativos e quantitativos) que permitissem a inferência de conhecimentos relativos às condições de produção/recepção de mensagens. Já o tratamento dos dados, inicialmente defrontamos as questões similares do questionário I (antes da intervenção) com o II (depois da intervenção). Nesse processo, os dados foram organizados e expostos em planiIhas, sendo, por conseguinte, produzidos os resultados em níveis estatísticos para a análise e discussão. Em relação aos dados colhidos por meio do POCC, utilizamos a Análise Visual de Movimento para criarmos quadros categóricos, subdivididos a partir da categorização do roteiro adotado, organizados e analisados de acordo com os objetivos propostos.

Aclaramos a submissão do projeto de pesquisa ao Comitê de Ética em Pesquisa com Seres Humanos (CEP) do Hospital Universitário Lauro Wanderley da Universidade Federal da Paraíba, sendo devidamente aprovada sob protocolo CEP/HULW n 190/09, FR-290813. Esclarecemos também que o Termo de Consentimento Livre e Esclarecido foi assinado por todos os participantes da pesquisa, obedecendo-se as diretrizes éticas da pesquisa com seres humanos recomendadas pela Comissão Nacional de Ética em Pesquisa (CONEP), Resolução 196/96 do Conselho Nacional de Saúde.

\section{ANÁLISES E DISCUSSÕES}

Em relação à apresentação e discussão dos dados coletados, recorremos aos questionários avaliativos e o protocolo de observação. Para o artigo em questão, priorizaremos a dimensão da exploração espacial e, como suporte para análise, utilizaremos gráficos que correspondem aos dados coletados, explicitando percentualmente os resultados obtidos. Os dados colhidos correspondem ao antes e depois da aplicação do seminário. O intuito foi de compararmos, por meio dos escores do grupo focal, as repercussões advindas das oficinas trabalhadas. Visando maior riqueza teórico-metodológica, mantemos nas falas e argumentações uma perspectiva crítico-reflexiva ancorada, sobretudo, no arcabouço teórico recorrido ao longo da pesquisa. Dialogaremos de maneira direta tanto com autores que exploram o saber comunicativo - tal como Picard (1986), Laban (1978), Knapp e Hall (1999), Weil e Tompakow (1986) -, como também aqueles que exploram o saber docente de maneira mais específica - como Freire (1999), Morin (1991; 1997; 2000), Tardif (2002), Sacristan (1999; 2005). O propósito especifico aqui é relacionar a proposta trabalhada com a teorização educacional que enfoca a ação interventiva docente.

A propósito da categoria avaliativa Corpo Espacial, ratificamos o foco da análise 
na capacidade de o sujeito explorar o espaço em que está inserido. Partimos da perspectiva do corpo como ferramenta interativa, que age e interage com o meio. Por nossa intervenção ser direcionada ao professor, procuramos oferecer uma aprendizagem que pudesse ser refletida em seu espaço pedagógico. Vale frisar que, para nosso estudo, caracterizamos Espaço Pedagógico com base, sobretudo, no pensamento de Freire (1999), sendo este uma esfera que compreende aquele que ensina e aquele que aprende, definindo certa relação entre eles. Para o autor, o espaço pedagógico representa um texto para ser constantemente "lido, interpretado, escrito e reescrito".

Baseando-nos em estudos referentes à performance cênica do ator, vinculamos a técnica de explorar o palco ao procedimento didático na sala de aula. Adotando conceitos e pensamentos que valorizam a expansão corporal no espaço que o contextualiza, seguimos a partir da vertente que analisa o corpo que se faz presente. Para isso, verificamos a capacidade de o sujeito explorar o espaço no qual está presente,

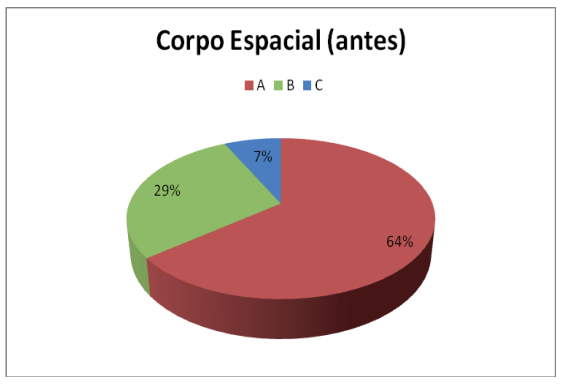

Gráfico 1: Corpo Espacial (antes) priorizando a dimensão espacial horizontal (perto e longe).

Nesta categoria avaliativa, como perspectiva de suporte, adotamos duas categorias da LMA', Forma ("com quem nos movemos?") e Espaço ("onde nos movemos?"). A primeira diz respeito aos relacionamentos ou com quem nos movemos. Considera as mudanças no volume do corpo em movimento, em relação a si mesmo ou a outros corpos. Os Modos de Mudanças de Forma (Modes of Shape Change) incluem: forma fluida, forma direcional ou arcada, e forma tridimensional. A segunda refere-se onde nos movemos. Conhecida também por Harmonia Espacial, envolve uma "arquitetura do espaço", criada por Laban a partir de seus estudos da "arquitetura do corpo", numa relação harmônica, envolvendo os seguintes conceitos, entre outros: harmonia espacial, cinesfera, alcance do movimento, formas cristalinas, percurso espacial e tensão espacial (FERNANDES, 2002). A seguir, os gráficos abaixo demonstram, em termos percentuais, a repercussão das atividades realizadas na Oficina IV.

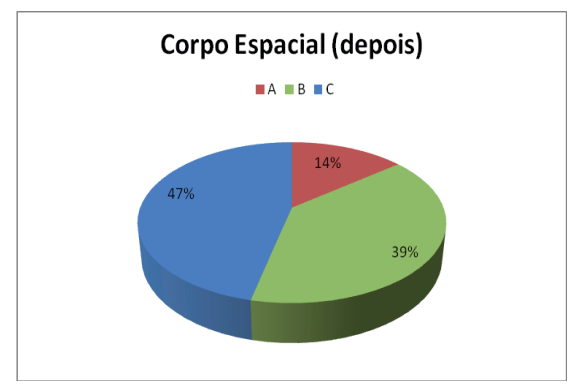

Gráfico 1.1: Corpo Espacial (depois)

6 A sigla LMA refere-se ao Sistema Análise Laban de Movimento (Laban Movement Analysis - LMA), desenvolvido por Rudolf Laban (1879-1958), dançarino, coreógrafo e considerado o maior teórico da dança do século XX. Tal sistema fora fundamental para nossa base teórico-metodológica, para a construção do nosso método avaliativo, bem como para o processo de análise e discussão dos dados. 
Antes de efetivamente discutirmos as informações passadas pelos gráficos (1 e 1.1), é fundamental que entendamos sua estrutura. Levaremos em conta que as cores explicitadas representam os níveis do indicador de comunicação não-verbal Exploração Espacial: vermelho (pouca); verde (razoável); e azul (considerável). Salientamos que o valor estimado em 100\% representa os 28 participantes pesquisados.

A partir do protocolo de observação, aplicado antes da intervenção corporal, notamos a predominância do nível pouca (64\%), seguido do nível razoável (29\%) e considerável (7\%). Isso implica dizer que, em se tratando do espaço em que o sujeito se encontra, nossos participantes da pesquisa apresentaram certas limitações ao explorá-lo (ocupá-lo). Trataremos delas mais a frente. O gráfico 1.1 expõe valores da pós-intervenção com perceptíveis alterações valorativas. Chamamos atenção para o que se refere ao nível pouca, que, de $64 \%$, declinou para o valor de $14 \%$, diluindo-se apreciavelmente nos níveis razoável (39\%) e considerável (47\%). Tais modificações sugerem a efetiva interferência dos trabalhos realizados na Oficina IV.

Abordando os fatores que consideramos responsáveis por tais alterações e partindo do princípio de que o espaço em que estamos inseridos existe para que o exploremos, nesta oficina trabalhamos a capacidade consciente de o participante ocupar o máximo de espaço possível, no intuito de dinamizar sua interação e, por consequência, sua Comunicação Corporal. Os dados iniciais, antes da intervenção, demonstram que mais da metade dos pesquisados não exploraram, de forma homogênea e satisfatória, o espaço que Ihes foi oferecido. Entretanto, após as atividades corporais oferecidas na oficina, este cenário se modificou relevantemente.

Um detalhe importante que deve ser ressaltado acerca dessa categoria é que, na aplicação do POCC, nenhum dos participantes sabia que estava sendo avaliado. Essa prerrogativa foi fundamental para a fidedignidade dos dados colhidos, de modo que, não sabendo da avaliação propriamente dita, dificilmente o participante esforçar-se-ia de maneira não espontânea para atingir níveis fora de sua capacidade intuitiva.

Para ter um concreto efeito na comunicação momentânea, o corpo deve, obrigatoriamente, ocupar o espaço em que se encontra, evidenciando uma relação entre sujeito e meio. Obviamente, nossa análise levou em consideração mais do que simplesmente deslocar-se no espaço. Consideramos o modo de interagir com o meio como uma espécie de diálogo de sensações, de sentidos. Concretizamos a filosofia de que se fazendo perceber no meio, o meio se fará perceber no sujeito (LABAN, 1978).

Outro importante fator desta categoria refere-se à sua diferenciação com a anterior, mais especificamente com o fator dinâmica entre corpo e ambiente. Neste fator, não obrigatoriamente o corpo deve ocupar o espaço. Ele pode dinamizar mesmo estático, sem deslocamento. O fundamental é que haja movimento. Já naquele, é primordial que o movimento tenha como lastro o deslocamento corporal.

Através de seus estudos, Greiner (2003) elucida a prerrogativa de que o corpo e ambiente são contaminados mutuamente ao invés de uma relação de influência ativo/ passivo. Refletindo sobre manifestações de dança, teatro e performance, a autora afirma que o "onde" deixou de ser apenas o lugar em que o corpo artista se apresenta. $\mathrm{Na}$ 
realidade, fora gradativamente se transformado em parceiro ativo dos experimentos cênicos. "Em vez de lugar, o onde se tornou uma espécie de ambiente contextual" (p. 51-52). De certo modo, encontramos similaridades entre o pensamento de Greiner (2003) e o de Laban (1978), o qual defende a correspondência entre corpo e mente em um ser completo, por meio de uma linguagem gestual simbólica e da interação entre corpo e espaço. Para Laban, cada tensão de movimento é expressiva de um ou mais sentimentos ou emoções correspondentes.

O diferencial entre as várias perspectivas do corpo no espaço está em como é acessado o "corpo subjetivado". Enquanto alguns seguem por caminhos que buscam a disciplina de um "treinamento" padronizado, outros optam pela liberdade intuitiva, trabalhando a partir de princípios que impulsionam a exploração, tornando o sujeito partícipe do contexto e não mero objeto. Para Laban (1978), a expressividade é um ponto primordial neste processo, pois se vincula à nossa energia, ao impulso interno. Por isso, tendo plena consciência de onde estamos indo no espaço, devemos observar e analisar como nós estamos indo e qual tipo de energia utilizamos para o movimento. Esse tipo muscular chamado de esforço é que determina como nós agimos, é o resultado de impulsos internos previamente experimentados.

Evidenciando o que para nós foi caracterizado como limitações dos sujeitos ao explorarem o espaço em que estavam inseridos, comprovamos dois fatores de redução do saber comunicativo: (a) percepção ampla do espaço; e (b) ocupação consciente e estratégica do espaço. Para expormos o conceito adotado no fator Percepção Ampla do Espaço, recorremos à linguagem artística cênica, a qual se faz veementemente presente na prática corporal. A partir de Koudela (2002), temos que a percepção ganha relevante importância no que se refere à exploração espacial. Segundo a autora, o ator, antes de encenar, deve previamente ter percebido o espaço em que se encontra. Isso refletirá em sua performance, em sua atuação. Logo, a pretensão de se explorar o espaço sem seu devido mapeamento (visual, logístico) acarreta vários distúrbios: insignificante ocupação, pouca exploração, movimentação dessincronizada (sem nexo, sem significado).

Encaramos a percepção do espaço como fator essencial para o início da interação entre sujeito e ambiente. Isso justifica a atenção necessária antes da efetiva exploração, considerando aspectos como dimensão espacial, contexto do ambiente, elementos que o compõem, tais como objetos, pessoas. Ancorando-nos em Novelly (1994), afirmamos ser fundamental o mapeamento logístico do espaço. Mas não tão somente através do sentido visual. O reconhecimento pode e deve acontecer por intermédio de outros sentidos, como tato e olfato, por exemplo. Faz-se necessária a habilidade de perceber e perceber-se no meio. Assim, com a devida percepção ampla do espaço, o sujeito cria uma base lógica e estratégica para explorar, de forma mais proveitosa e com maior significação, o espaço que ocupa.

Em relação ao fator Ocupação Consciente e Estratégica do Espaço, seguindo a mesma lógica do fator anterior, é fundamental que a ocupação do espaço ocorra, inicialmente, de forma consciente. Inicialmente, porque o ideal é que a prática venha de forma natural, condizendo com a necessidade do momento. Entretanto, a 
assimilação deve ser gradativa. Primeiramente a percepção, depois a ocupação, exploração, conscientização e estratégia. Nas atividades propostas, buscamos mostrar que a exploração espacial pode amplificar a Comunicação Corporal, no sentido de que, interagindo com o meio, a informação ganha maior repercussão visual, perceptiva, interpretativa (WEIL; TOMPAKOW, 1986). No entanto, além de consciente, a prática pode ser potencializada se realizada de forma estratégica.

A partir do momento em que o sujeito percebe o meio (espaço) e o ocupa, a exploração já pode proceder. A logística perceptiva proporciona a capacidade da elaboração estratégica. Isto é, se existe a possibilidade de fazer-se entender melhor deslocando-se para um determinado ponto do espaço, isso, teoricamente, deve ser feito. Se a propagação da voz será mais eficiente posicionando-se mais a frente do ponto inicial, dirigir-me-ei até ele. Esta é a lógica que contextualiza a estratégia de espaço. Explorar de forma consciente almejando resultados mais eficazes.

\section{CONSIDERAÇÕES FINAIS}

A partir dos resultados obtidos, constatamos a dimensão repercussiva ao trabalharmos diretamente com o corpo. A análise em foco ratifica o valor da comunicação corporal por meio da devida ocupação e exploração do espaço em que o sujeito está inserido, promovendo diferentes funções daqueles que interagem no ambiente. Confrontando as teorias recorridas com a prática realizada, é possível perceber que o corpo é fruto de uma subjetividade rica em elementos não concretos, não racionalizáveis. Daí a necessidade de novos mapeamentos que revelem suas nuanças e compreendam, dentre outras coisas, sua identidade expressada pela gestualidade, postura e sua ocupação no espaço.

De forma geral, considerando a intervenção em sua totalidade, obtivemos a concretude de uma ação corporal possível de ser modificada, alterada, provocada. Os sujeitos participantes da pesquisa obtiveram mudanças qualitativas em sua ação comunicativa corporal, sobretudo, naquilo que se refere: à timidez, mostrando-se mais disposto a se comunicar, a interagir; a relação entre intencionalidade e expressividade, manifestando-se de forma mais expressiva, gestualmente, evidenciando suas intencionalidades; e a sensibilidade da interação comunicativa, reconhecendo, a priori, a importância da interação social, e, num segundo plano, a valorização do ato de comunicar-se claramente por meio de seus gestos.

Especificando o canal comunicativo tratado neste artigo, Exploração Espacial, constatamos significativas contribuições pedagógicas que são facilmente transpassadas para o âmbito escolar, principalmente no que se refere à relação dinamizada entre corpo e meio. Do ponto de vista educativo, reconhecendo e entendendo a relação existente entre corpo e meio no qual está inserido, é possível oportunizar uma comunicação mais efetiva. Ancorando-nos em Tardif (2002), consideramos que o saber do professor é transmitido por meio de diferentes ambientes e situações, os quais incorporam as necessidades deste saber. Desse modo, entender o meio em que se insere é oportunizar-se melhor a interação com e por meio dele. 
Neste contexto, é importante o professor saber e fazer-se presente no ambiente em que atua. Para isso, é fundamental que tenha plena noção de suas implicações com o meio, considerando-se aliado no processo de ação pedagógica. Interagir com o meio vai muito além de estar nele, de ocupá-lo. É percebê-lo em toda a sua completude, é aproveitá-lo de maneira consciente e estratégica, intencionando melhorar e aproveitar ao máximo as condições da aula, de modo a obter os melhores resultados possíveis. Percebendo o espaço, o professor poderá melhor intervir nele.

Agradecimento: A Coordenação de Aperfeiçoamento de Pessoal de Nível Superior (CAPES), pelo suporte dado ao estudo.

\section{REFERÊNCIAS}

ARGYLE, Michael. Bodily communication. (2nd. Ed.). New York: Methuen \& Co. 2nd. Ed, 1988.

BERTHERAT, Thérèse. $\mathbf{O}$ corpo tem suas razões: antiginástica e consciência de si. São Paulo: Martins Fontes, 2008.

CASARES, Maria Inês Monjas; CABALHO, Vicente E. A timidez infantil. In: SILVARES, Edwiges Ferreira de Mattos (Org.). Estudos de caso em psicologia clínica comportamental infantil. Campinas, SP, Papirus, 2000.

CORRAZE, Jacques. As comunicações não verbais. Rio de Janeiro: Zahar, 1982.

FERNANDES, Ciane. O Corpo em Movimento: o sistema Laban/Bartenieff na formação e pesquisa em artes cênicas. São Paulo: Anablume, 2002.

FOUCAULT, Michel. Vigiar e punir. 7. ed. Petrópolis: Vozes, 1987.
FREIRE, João Batista. Educação de corpo inteiro: teoria e prática da Educação Física. São Paulo: Scipione, 2009.

FREIRE, Paulo. Pedagogia da autonomia. Rio de Janeiro: Paz e Terra, 1999.

GLUSBERG, Jorge. A arte da performance. São Paulo: Perspectiva, 2003.

KATZ, Helena; GREINER, Christine. Corpomídia: a questão epistemológica do corpo na área de comunicação. Revista Húmus, n. 1. Caxias do Sul: Secretaria Municipal de Cultura, 2004. KNAPP, Mark L.; HALL, Judith A. Comunicação não verbal na interação humana. Tradução de Mary Amazonas Leite Barros. São Paulo: JSN, 1999.

KUNZ, Elenor. Transformação didáticopedagógica do esporte. 6a.. ed. Ijui: Editora Unijui, 2004. v. 01. 160p.

LABAN, Rudolf. Domínio do Movimento. São Paulo: Summus, 1978.

MEDINA, João Paulo Subirá. A Educação Física cuida do corpo... e "mente". 15 a Ed. Campinas: Papirus, 2001.

MERLEA U - PONTY, Maurice. Fenomenologia da percepção. Tradução de Carlos Alberto Ribeiro de Moura. São Paulo: Martins Fontes, 1999.

MORIN, Edgar. Amor, poesia e sabedoria. RJ: Bertrand Brasil, 1997.

Introdução ao pensamento complexo. Lisboa, Instituto Piaget, 1991.

Os sete saberes necessários à educação do futuro. São Paulo: Cortez; Brasília: Unesco, 2000.

PEASE Allan; PEASE, Barbara. Desvendando os segredos da linguagem corporal. Rio de Janeiro: Sextante, 2005.

PICARD, Dominique. Del código al deseo: el cuerpo en la relación social. Buenos Aires: Paidos, 1986. 
RECTOR, Mônica; TRINTA, Aluizio Ramos. A comunicação não verbal: a gestualidade brasileira. Petrópolis: Vozes, 1985.

SACRISTÁN, José Gimeno. Poderes instáveis em Educação. Trad. de Beatriz Affonso Neves. Porto Alegre: Artes Médicas, 1999.

. O aluno como invenção.

Tradução de Daisy Vaz de Moraes. Porto Alegre: Artmed, 2005.
TARDIF, Maurice. Saberes docentes e formação profissional. Petrópolis, RJ: Vozes, 2002.

TREBELS, Andréas H. Uma concepção dialógica e uma teoria para o movimento humano. Perspectiva, v. 21, n. 1, jan./jun., 2003.

WEIL, Pierre; TOMPAKOW, Roland. O corpo fala: a linguagem silenciosa da comunicação não verbal. Rio de Janeiro: Vozes, 1986.

COMMUNICATIVE BODY: analyzing the bodily communication through the educator's space exploration

\begin{abstract}
From the perspective of the body as perception and expression of the subject in the world, this article analyzes the bodily communication of the educator as a primary source of information and constant. This is a descriptive, qualitative study, participant type, with 28 physical education teachers. The results showed the concreteness of a bodily action can be brought about and changed, seeing the pedagogical potential with regard to proper and conscious space exploration by the research subjects. It was also concluded that the surrounding space is characterized as pedagogical scenario to that which purports to teach.
\end{abstract}

Keywords: Education; Physical Education; Bodily communication. 


\section{APÊNDICES}

Apêndice A - Questionário de avaliação (antes)

Visando um melhor direcionamento de conteúdos e também para que tenhamos uma maior riqueza de dados comparativos e analíticos, responda as questões abaixo.

1) Qual o seu parecer em relação a sua profissão de Educador nos dias atuais?

2) Você acredita na Educação Física escolar atual? Comente.

3) Qual sua maior dificuldade no momento em que está ministrado as aulas? Defina em palavras isoladas.

4) Em que grau você acha que está seu nível de RELAÇÃO com seu alunos?

a. Bom, mas pode melhorar.

b. Bom o suficiente para atender ao que considero essencial.

c. Muito bom, precisando apenas de um aperfeiçoamento.

5) Em que grau você acha que está seu nível de INTERAÇÃO com seu alunos?

a. Bom, mas pode melhorar.

b. Bom o suficiente para atender ao que considero essencial.

c. Muito bom, precisando apenas de um aperfeiçoamento.
6) Em que grau você acha que está seu nível de COMUNICAÇÃO com seu alunos?

a. Bom, mas pode melhorar.

b. Bom o suficiente para atender ao que considero essencial.

c. Muito bom, precisando apenas de um aperfeiçoamento.

7) Em no máximo 5 linhas, comente o que você sabe sobre comunicação corporal?

8) Você acha que é possível otimizar a comunicação por meio do corpo?

9) Para você, o que significa a afirmação "O corpo fala"?

10) De 1 a 5 , qual nota daria para sua capacidade comunicativa corporal como Educador Físico escolar. Comente a razão da nota.

Apêndice B - Questionário de avaliação (depois)

Visando a avaliação de tudo que foi proposto ao longo do Curso de Formação e também para que tenhamos uma maior riqueza de dados comparativos e analíticos, responda as questões abaixo.

1) Marque abaixo em que grau percentual você acredita ter estado comprometido com o curso?
a. $100 \%$.
b. $70 \%$.
c. $50 \%$. 
d. Poderia ter me comprometido mais.

2) Em que grau você acha que o Seminário contribuiu para sua atuação como Educador?
a. Bastante.
b. Muito.
c. Pouco.

3) Você acredita que suas aulas tiveram algum reflexo de nosso projeto?
a. Bastante.
b. Muito.
c. Pouco.

4) Você acha que seu nível de RELAÇÃO com seus alunos melhorou depois do Seminário?
a. Bastante.
b. Muito.
c. Pouco.

5) Você acha que seu nível de INTERAÇÃO com seus alunos melhorou depois do Seminário?
a. Bastante.
b. Muito.
c. Pouco.

6) Você acha que seu nível de COMUNICAÇÃO com seus alunos melhorou depois do Seminário?
a. Bastante.
b. Muito.
c. Pouco,

7) Quão contribuiu o Seminário para seu conhecimento acerca da comunicação corporal? Marque a opção que melhor lhe satisfaz:

a. Boa parte do que foi trabalhado eu já sabia.

b. Aprendi pouco para o que esperava.

c. Apesar de saber um pouco sobre, pude aprender bastante.

d. Foi extremamente enriquecedor.

8) Você acha que depois do curso você passou a ser alguém que se COMUNICA melhor por meio do corpo?

a. Certamente. b. Sim. c. Talvez. d. Não.

9) De alguma forma, você acha que o seminário realizado trouxe algum benefício imediato para sua ação como professor escolar?

a. Certamente. b. Sim. c. Talvez. d. Não

10) Você acha que seria bom para a Educação Física escolar de Cabedelo uma continuidade desses tipos de trabalho?
a. Certamente.
b. Sim.
c. Talvez.
d. Não vejo contribuição alguma. 
Apêndice C - Protocolo de Observação do Corpo Comunicativo (POCC)

\section{PROTOCOLO DE OBSERVAÇÃO DO CORPO COMUNICATIVO (POCC)}

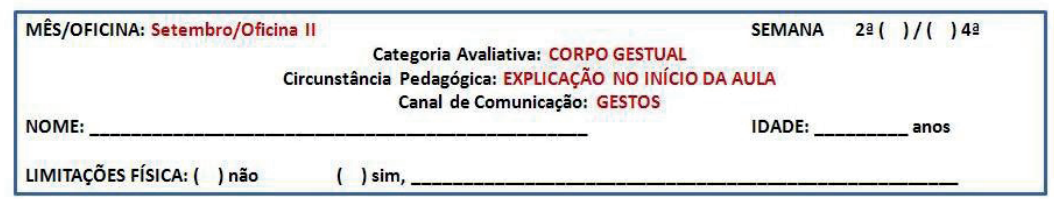

\section{SEMANA (avaliação do ANTES)}

Categoria de Análise:

Expressividade Gestual

A( ) Regular-De 1 a 2 palavras-chave

B( ) Boa - De 3 a 4 palavras-chave

C( ) Excelente-De 5 a 6 palavras-chave

\section{4a SEMANA (avaliação do DEPOIS)}

Categoria de Análise:

Expressividade Gestual

A( ) Regular- De 1 a 2 palavras-chave

B( ) Boa-De 3 a 4 palavras-chave

C( ) Excelente-De 5 a 6 palavras-chave

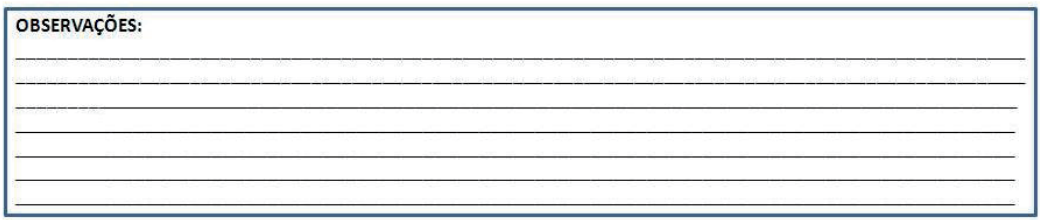

PROTOCOLO DE OBSERVAÇÃO DO CORPO COMUNICATIVO (POCC)

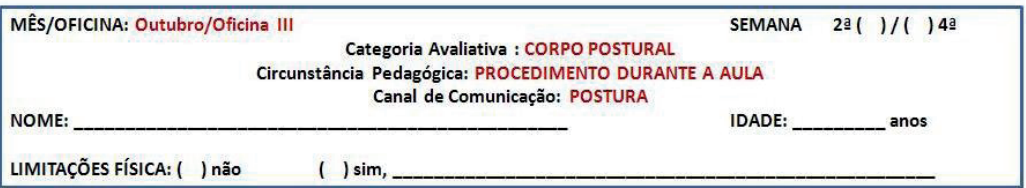

\section{2a SEMANA (avaliação do ANTES)}

Categoria de Análise:

Expressividade Postural

A1( ) A2 ( ) Regular-De 5 a 10 movimentos

B1( ) B2( ) Boa-De 10 a 15 movimentos

C1( ) C2 ( ) Excelente-De 15 a 20 movimentos

\section{4a SEMANA (avaliação do DEPOIS)}

Categoria de Análise: Expressividade Postural

A1( )A2 ( ) Regular-De 5 a 10 movimentos

B1( )B2( ) Boa-De 10 a 15 movimentos

C1( ) C2 ( Excelente-De 15 a 20 movimentos

\begin{tabular}{|l|}
\hline OBSERVAÇ̃̃ES: \\
\hline \\
\hline \\
\hline \\
\hline
\end{tabular}




\section{PROTOCOLO DE OBSERVAÇÃO DO CORPO COMUNICATIVO (POCC)}

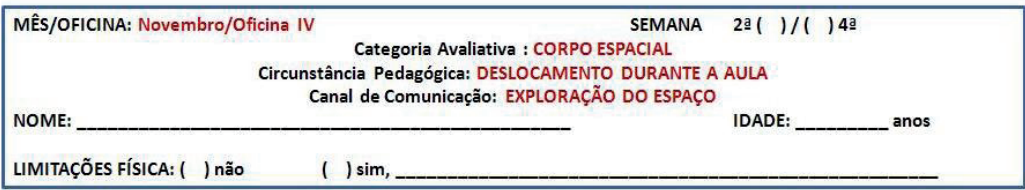

\begin{tabular}{|l|l|}
\hline \multicolumn{1}{|c|}{ 2 a SEMANA (avaliação do ANTES) $^{-1}$ 4a SEMANA (avaliação do DEPOIS) } \\
\hline Categoria de Análise: & Categoria de Análise: \\
\hline Exploração do Espaço (EE) & Exploração do Espaço (EE) \\
A ( ) Pouca EE - De 0 a 3 pontos & A( ) Pouca EE - De 0 a 3 pontos \\
B( ) Razoável EE - 4 a 6 pontos & B( ) Razoável EE - 4 a 6 pontos \\
C( ) Considerável EE - De 7 a 8 pontos & C( ) Considerável EE - De 7 a 8 pontos \\
\hline
\end{tabular}

\section{OBSERVAÇõES:}

